\title{
Tracking genetic diversity in a large-scale oyster restoration program: effects of hatchery propagation and initial characterization of diversity on restored vs. wild reefs
}

\author{
Katherine M. Hornick $\mathbb{1}^{1} \cdot$ Louis V. Plough ${ }^{1}$
}

Received: 9 October 2018 / Revised: 18 January 2019 / Accepted: 11 February 2019 / Published online: 4 March 2019

(c) The Genetics Society 2019

\begin{abstract}
The release of hatchery-propagated fish and shellfish is occurring on a global scale, but the genetic impacts of these practices are often not fully understood and rarely monitored. Slow recovery of depleted eastern oyster populations in the Chesapeake Bay, USA has prompted a hatchery-based restoration program focused in the Choptank River, Maryland consisting of the mass release of hatchery-produced juveniles from local, wild broodstock. To evaluate potential genetic effects of this program, we (1) examined changes in genetic diversity (allelic richness, heterozygosity) and the effective number of breeders $\left(N_{\mathrm{b}}\right)$ over the hatchery production cycle with microsatellite-based parentage of natural, mass- and controlledspawned cohorts, and (2) compared genetic diversity and effective population size $\left(N_{\mathrm{e}}\right)$ of a restored reef to wild source populations. Mass-spawned cohorts showed high variance in reproductive contribution, particularly among males, leading to a $45 \%$ average reduction in $N_{\mathrm{b}}$ from spawning adult numbers and higher relatedness-lower magnitude reductions in heterozygosity and significant reductions in allelic richness were also observed. While controlled-spawns (single-male fertilizations of pooled eggs) reduced male variance, overall reproductive variance $\left(V_{\mathrm{k}}\right)$ remained high. Finally, oysters sampled from a restored reef displayed comparable $N_{\mathrm{e}}$, genetic diversity, and relatedness to samples from wild populations, with no significant genetic differentiation among them. Overall, the hatchery-based results and initial field-based population genetic analyses suggest that despite reductions in diversity from parents to offspring owing to high $V_{\mathrm{k}}$, enhancement with rotated, wild broodstock appears to have maintained genetic diversity in a restored reef population compared to proximal wild populations.
\end{abstract}

\section{Introduction}

Large-scale releases of plant and animal populations has increased worldwide to augment overexploited fisheries, forests, and wildlife (e.g., Laikre et al. 2010). For coastal fisheries, which have seen sharp declines over the last half century (Jackson et al. 2001; Myers and Worm 2003), the release of hatchery-propagated stocks has become an

Supplementary information The online version of this article (https:// doi.org/10.1038/s41437-019-0202-6) contains supplementary material, which is available to authorized users.

Katherine M. Hornick

Katie.hornick@gmail.com

1 University of Maryland Center for Environmental Science, Horn Point Laboratory, 2020 Horns Pt. Rd., Cambridge, MD 21613, USA important component of fisheries management strategies, used for restocking, stock enhancement, or ranching in $100 \mathrm{~s}$ of species around the world (see Bell et al. 2008 for definitions; Laikre et al. 2010; Lorenzen et al. 2012). Restocking aims to re-establish a locally extinct commercial species and/or to restore depleted spawning biomass to a level where it can provide regular substantial yields, whereas stock enhancement aims at sustaining or improving fisheries in the face of decline (Bell et al. 2008; Lorenzen et al. 2012). Although the genetic risks associated with restocking and stock enhancement have been well described (e.g., Blankenship and Leber 1995; Lorenzen et al. 2012), these programs are rarely monitored (Laikre et al. 2010).

Restocking and stock enhancement are effective at increasing the abundances of depleted or declining populations in the short-term, but these programs risk dramatically altering the genetic composition and diversity of populations, which can negatively impact long-term population resilience (reviewed in Frankham et al. 2010). For 
example, unintentional domestication selection (Frankham 2008) can result in the release of individuals with adaptive mismatches to local environmental conditions (e.g., Waal et al. 2013), and reduced fitness compared with their wildborn counterparts (Araki et al. 2007, 2008). Programs using a reduced number of broodstock can cause reductions in wild population genetic diversity and effective population size $\left(N_{\mathrm{e}}\right)$, leading to increased rates of genetic drift and increased potential for inbreeding, thereby limiting evolutionary potential (e.g., Allendorf and Ryman 1987; Christie et al. 2012). When hatchery $N_{\mathrm{e}}$ is lower than wild (recipient) $N_{\mathrm{e}}$ and reproductive contribution to wild populations is high, reductions in diversity of wild populations can be acute, producing the so-called Ryman-Laikre effect, which is a concern for the enhancement of salmonids and other fish (Ryman and Laikre 1991; Gold et al. 2008; Christie et al. 2012). Genetically aware, "conservation-based" strategies are increasingly used in enhancement and/or restocking programs to maintain high-diversity, selfsustaining populations (e.g., Caughley and Gunn 1996; Heggenes et al. 2006). However, less is known about the long-term genetic impacts of these programs and genetic monitoring is often limited or absent (e.g., Laikre et al. 2010)

Restoration of marine shellfish populations, primarily through juvenile seeding (Gaffney 2006; Laing et al. 2006), is increasing as coastal populations succumb to habitat degradation and overfishing (e.g., Beck et al. 2011). Although the potential for diversity loss is widely appreciated, monitoring is rare and few studies of the genetic impacts of these programs have been conducted (e.g., Gaffney 2006; Camara and Vadopalas 2009). Characteristics of marine shellfish life-history, including high fecundity, high early mortality, and high variance in reproductive success (e.g., Hedgecock and Pudovkin 2011; Plough 2016; Plough et al. 2016), may exacerbate many of the underlying genetic risks associated with restocking or restoration, and can limit $N_{\mathrm{e}}$ to a small fraction of the census population size (He et al. 2012). Few studies have attempted to connect genetic changes in the hatchery (larval) phase to the genetic composition and diversity of wild or restored populations (but see Hanley et al. 2016), and less is known about the Ryman-Laikre effect in iteroparous species like shellfish (Waples et al. 2016). A number of laboratory studies have examined diversity during the larval stages of shellfish species (e.g., Boudry et al. 2002; Lind et al. 2009; Lallias et al. 2010), but less work has been done to connect these changes in the hatchery phase to the genetic composition and diversity in wild or restored populations. Except for work by Morvezen et al. (2016), there is a dearth of data on the genetic changes associated with shellfish hatcherybased enhancement and/or restocking programs from field samples or experiments, and no studies have monitored the genetic impacts of an intensive restoration program.

In this study, we examined the genetic impacts of a largescale restoration program for the eastern oyster Crassostrea virginica (Gmelin, 1791) in the Chesapeake Bay, with two primary objectives: (1) to characterize how genetic diversity changes during the hatchery production phase under two natural spawning protocols, and (2) to examine how genetic diversity of a restored reef population compares to surrounding wild reefs, to provide an initial assessment of how genetic diversity has been maintained or lost as a result of the restoration program. Oysters once supported major fisheries along the US East Coast but have declined to $<1 \%$ of their historic abundances due to overfishing, habitat destruction, and disease (Newell 1988; Rothschild et al. 1994). In the Chesapeake Bay, historically one of the most productive oyster fisheries on the US East Coast, oyster restoration activities of various sizes have been undertaken over the last half century to restore the fishery and ecosystem services provided by oyster reefs (e.g., Kennedy et al. 2011). Recently, a federal mandate to restore 20 Chesapeake Bay tributaries by 2025 has provided support for more comprehensive restoration in the Choptank River region (Maryland, USA), with the first of three sub-tributaries, Harris Creek (MD), completed in 2016 (Westby et al. 2017). The University of Maryland Center for Environmental Science's (UMCES) Horn Point Laboratory (HPL) Oyster Hatchery has been producing spat (juvenile oysters) on shell for the Harris Creek Sanctuary (and other locations), through natural (temperature-stimulated) group or "mass" spawning of wild Choptank River broodstock (e.g., Wallace et al. 2008). However, no genetic monitoring of this program has been conducted, and the potential impacts of spawning protocol, hatchery propagation, and planting on genetic diversity are unknown.

To quantify genetic changes during hatchery production (objective 1), we conducted parentage analyses on six massspawned cohorts and three controlled-spawned cohorts (isolated natural spawns with single-male fertilizations) using up to nine microsatellite markers. Parental contribution (variance in reproductive success) and genetic diversity metrics, including effective number of breeders, were calculated in the offspring at the spat (planting) stage and compared with their parents. To quantify the broader population genetic impact of this restoration program (i.e., genetic diversity in restored vs wild populations; objective (2), we estimated and compared $N_{\mathrm{e}}$, genetic diversity metrics, and relatedness among five wild broodstock sources, an aquaculture line, and a restored Harris Creek reef sample planted in 2012, to provide an initial assessment of how diversity is maintained following enhancement with hatchery-produced cohorts. This work provides important 
Table 1 Detailed cohort information of $C$. virginica populations used in this study

\begin{tabular}{lllllll}
\hline Cohort & Source & $N$ & Females & Males & $\begin{array}{l}\text { Offspring } \\
\text { sampled }\end{array}$ \\
\hline M1 & Sandy Hill (SH1) & $38.60 \mathrm{~N},-76.13 \mathrm{~W}$ & 23 & 16 & 7 & 120 \\
M2 & Sandy Hill (SH2) & $38.59 \mathrm{~N},-76.10 \mathrm{~W}$ & 21 & 15 & 6 & 120 \\
M3 & Sandy Hill (SH3) & $38.60 \mathrm{~N},-76.12 \mathrm{~W}$ & 21 & 11 & 10 & 120 \\
M4 & Chlora Point & $38.63 \mathrm{~N},-76.14 \mathrm{~W} ; 38.63 \mathrm{~N}$, & 22 & 10 & 12 & 115 \\
& (CLP) & $-76.15 \mathrm{~W}$ & & & & \\
M5 & Black Buoy & $38.58 \mathrm{~N},-76.04 \mathrm{~W}$ & 34 & 11 & 23 & 115 \\
& (BBY) & & 20 & & 11 & 115 \\
M6 & Louisiana (LoLA) & NA & 15 & 7 & 8 & 120 \\
C1 & States Bank (TB) & $-76.04,38.57$ & 15 & 7 & 8 & 120 \\
C2 & States Bank (TB) & $-76.04,38.57$ & 15 & 7 & 8 & 120 \\
C3 & States Bank (TB) & $-76.04,38.57$ & & & & \\
\hline
\end{tabular}

M1-M6 represent the mass-spawned cohorts; C1-C3 represent the controlled-spawned cohorts baseline data for monitoring genetic diversity of oyster restoration efforts in Chesapeake Bay, and more broadly, for examining genetic impacts of other large-scale shellfish restoration efforts ongoing or planned in the US (e.g., Holley et al. 2018; Brumbaugh and Coen 2009; Dinnel et al. 2009).

\section{Materials and methods}

\section{Spawning methods, collection of broodstock or hatchery sources, and sampling of spat}

Oyster cohorts (offspring from mass- and controlled-spawns) were produced at the UMCES HPL Oyster Hatchery in Cambridge, MD, USA over the summers of 2014-2016. Wild Choptank River broodstock was used for the production of all cohorts (Table 1), except for cohort M6, which was produced from the Louisiana-derived "LoLA" aquaculture line, obtained from the Aquaculture Genetics and Breeding Technology Center (ABC) at the Virginia Institute of Marine Sciences. All broodstock were conditioned in the HPL Oyster Hatchery at ambient salinity and $20^{\circ} \mathrm{C}$ for $6-8$ weeks prior to spawning. The HPL Oyster Hatchery produces all spat on shell for restoration planting using a mass-spawn protocol, and thus, we followed their protocols for the mass-spawned cohorts.

For the mass-spawned cohorts (M1-M6; Table 1), groups of $\sim 50$ ripe broodstock were placed in an open aquarium (spawning table) with heated $\left(\sim 28-30^{\circ} \mathrm{C}\right)$ flowthrough filtered Choptank River water ( 10-12 ppt; hereafter seawater) to initiate spawning. As oysters spawned, females and males were removed from the spawning table and placed into separate containers (one for all males and one for all females) and allowed to finish spawning. When spawning ceased, pooled eggs were counted volumetrically, and an appropriate amount of pooled sperm was used to fertilize the pool of eggs (Galtsoff 1964). For all massspawned cohorts, spawning order was recorded for males and females and fertilization occurred no more than $45 \mathrm{~min}$ after the first oyster was observed to spawn. For the controlled-spawned cohorts (C1-C3; Table 1), broodstock oysters were placed in individual $1.8 \mathrm{~L}$ aquaria (Aquaneering, San Diego, CA) arranged on a multi-tiered rack with heated, flowing seawater (independent in- and out-flow for each vessel). When evidence of spawning was observed, water to the particular aquaria was turned off to allow gamete accumulation. The time of spawning for each oyster was noted. Once a sufficient number of spawning males and females were identified, eggs were pooled, counted volumetrically, and divided evenly among eight containers (the number of males that spawned) for individual male fertilizations (no sperm competition). Cohorts M1-M3 were spawned in June 2014, M4-M6 in June 2015, and C1-C3 in July 2016. Tissue samples (adductor muscle or mantle) were collected from all adult broodstock and preserved in 70-95\% ethanol. All broodstock adults (LoLA and wild) were also utilized in the population genetic analyses of diversity, population structure, and $N_{\mathrm{e}}$ (see below). In addition, 48 adult oysters (mixed-age classes) were sampled from a restored reef in the Harris Creek Sanctuary (Seed 2; $38.71298 \mathrm{~N},-76.31985 \mathrm{~W}$ ) in 2015, which had been planted with hatchery-produced oysters in 2012 (Fig. 1). All details concerning the larval culturing and juvenile nursing are presented in the Supplementary Materials and Methods.

Whole individual spat were randomly sampled from each cohort and stored in tissue lysis buffer at $-80{ }^{\circ} \mathrm{C}$ prior to extraction. One hundred twenty spat were sampled for cohorts M1-M3 and C1-C3, and 115 spat were sampled for cohorts M4-M6 (Table 1). 
Fig. 1 Map of the Chesapeake Bay showing the approximate locations of wild $C$. virginica broodstock sources from the Choptank River (Chesapeake Bay inset) and the Harris Creek Sanctuary. 'CLP' is Chlora Point., 'SH' is Sandy Hill, 'BBY' is Black Buoy, 'TB' is States Bank and ' $\mathrm{HC}$ ' is the Harris Creek Sanctuary site

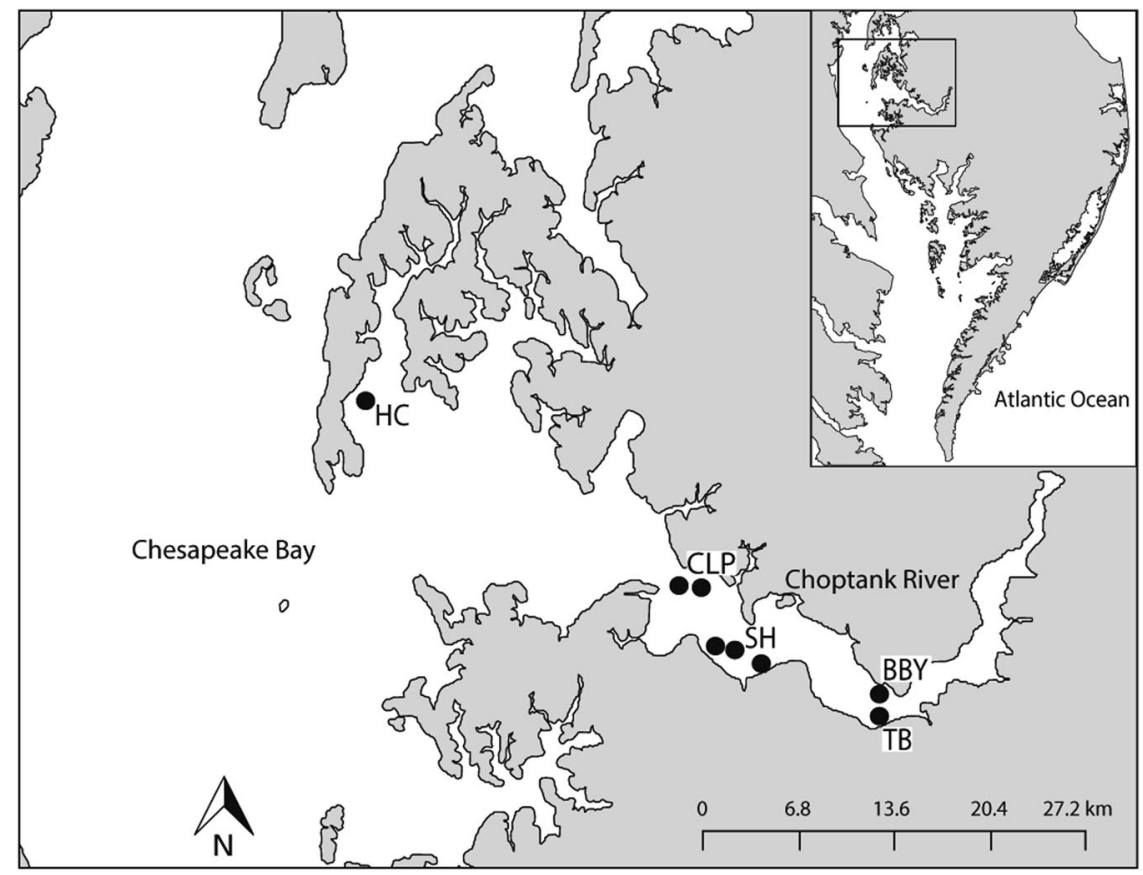

\section{DNA extraction and microsatellite genotyping}

DNA was extracted from adult tissue and spat using the E. Z.N.A. ${ }^{\oplus}$ Tissue DNA Kit (Omega-Biotek, Norcross, GA) or the Qiagen DNeasy Tissue kit (Qiagen Inc, Valencia, CA), following the protocol for animal tissues. DNA concentrations were estimated using a Qubit Fluorometer (Thermo Fisher Scientific Inc., Waltham, MA, USA) and all samples

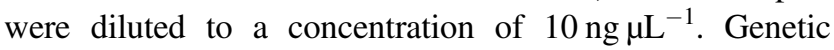
analysis was conducted on nine microsatellite loci previously developed by Brown et al. (2000), Reece et al. (2004), Carlsson and Reece (2007), Wang and Guo (2007), and Wang et al. (2009) and were named as in the source publication (see Supplementary Table S1 for loci ID). Samples from the restored Harris Creek reef and cohorts M1-M6 (broodstock parents and offspring) were genotyped at all nine microsatellite loci while cohorts $\mathrm{C} 1-\mathrm{C} 3$ were genotyped at six of these loci (Supplementary Table S1). Polymerase chain reactions were carried out in volumes of $12.5 \mu \mathrm{l}$ with $1 \times$ GoTaq $^{\circledR}$ flexi PCR buffer (Promega, Madison, WI, USA), $200 \mu \mathrm{m}$ dNTPs, $0.04 \mu \mathrm{m}$ of the M13tailed forward primer, $0.16 \mu \mathrm{M}$ of both the reverse primer and the M13 fluorescent dye-labeled primer, and 1.25 units of GoTaq ${ }^{\circledast}$ Flexi DNA Polymerase (Promega, Madison, WI, USA). The PCR cycling program was run in two phases; the first to amplify the target microsatellite marker, and the second to incorporate a fluorescently labeled dye attached to the M13 tag sequence (see Schuelke 2000 for details).

Microsatellite PCR products were pooled, precipitated, and shipped dry to the Arizona State University DNA Laboratory, where fragment analysis was performed on an
ABI 3730 capillary sequencer. Genotypes were scored by eye using the LIZ500 (Applied Biosystems) as an internal size standard on the Peak Scanner v1.0 software (Applied Biosystems) and verified using Genemapper (Applied Biosystems). For each cohort, $25 \%$ of the offspring were genotyped in duplicate to calculate genotype error rate at each locus.

\section{Parentage assignment}

Parentage assignment was performed in CERVUS v.3.0.7 (Marshall et al. 1998; Kalinowski et al. 2007) using the parent-pair analysis option and the Delta method. For each cohort, simulations in CERVUS were run to estimate the critical values of Delta for each cohort with strict (95\%) and relaxed (80\%) levels of statistical confidence in assignment (Kalinowski et al. 2007). Each set of simulations was specific to the number of loci typed, the number of candidate parents, and the locus error rates for that particular cohort. Putative candidate parent pairs were considered accurate if the offspring-dam-sire trio statistical confidence was $\geq 95 \%$ (strict confidence). We excluded individuals assigned at relaxed confidence $(80 \%)$, or those that were not assigned at all, from downstream analysis.

\section{Effective number of breeders $\left(N_{b}\right)$ and related statistical analyses}

After assigning offspring to broodstock parent pairs, the mean number of offspring $(\bar{k})$ per parent and variance in reproductive success $\left(V_{\mathrm{k}}\right)$ was calculated for male and 
female broodstock from each cohort. $V_{\mathrm{k}}$ was standardized by the mean number of offspring in a family $\left(\sigma^{2} / \mu^{2}\right)$ and is reported as such from here on. From these parameters, the inbreeding number of breeders $\left(N_{\mathrm{bI}}\right)$ was estimated for each sex following equations 1 and 2 from Christie et al. (2012). Equation 6 from Waples and Waples (2011) was used to estimate $N_{\mathrm{b}}$ (hereafter $N_{\mathrm{bS}}$ ) using information from sibship reconstruction analysis in COLONY v2.0.6.1 (Jones and Wang, 2010). We then compared the estimated $N_{\mathrm{bI}}$ to the number of successful broodstock spawned $(N)$ for all cohorts. Differences in $V_{\mathrm{k}}$ between males and females were tested within each cohort using a two-tailed parametric Ftest in R (R Core Team 2017). Skew in reproductive contribution of males and females was assessed via Chi-square goodness-of-fit tests in R, with the null hypothesis of equal reproductive contribution.

\section{Population genetic analyses and statistical comparisons}

Allelic richness $\left(\mathrm{A}_{\mathrm{r}}\right)$ for each locus and cohort was calculated in FSTAT v2.9.3.2 (Goudet 2002), which uses a sample-size independent rarefaction analysis of allelic richness. Observed heterozygosity $\left(H_{\mathrm{o}}\right)$ was calculated in the R package "hierfstat" (Goudet 2005). Tests for Hardy-Weinberg equilibrium (HWE) were performed in GenoDive v2.0b27 (Meirmans and Van Tienderen 2004) using 9999 one-sided permutation tests, with $P$ values corrected for multiple tests via sequential Bonferroni correction (Rice 1989). For markers that differed significantly from HWE, null allele frequencies were estimated using Microchecker v.2.2.3 (Van Oosterhout et al. 2004) and FreeNA (Chapuis and Estoup 2007). To test whether parents and offspring from a given cohort differed in genetic diversity metrics $\left(\mathrm{A}_{\mathrm{r}}, H_{\mathrm{o}}\right)$, paired Wilcoxon signed-rank tests between parents and offspring were performed (see Nei 1987, p. 183), with $P$ values adjusted for multiple tests using the false discovery rate correction (Benjamini and Hochberg 1995). Relatedness was estimated for parents and offspring (grouped by broodstock source) from hatchery cohorts and for the Harris Creek sample using the Lynch and Ritland method (Lynch and Ritland 1999) in COANCESTRY v1.0 (Wang 2011), because it performs well in panmictic populations (e.g., Oliehoek et al. 2006).

Contemporary effective population sizes $\left(N_{\mathrm{e}}\right)$ were calculated for adult broodstock source populations, hatcheryproduced oysters, and a restored population from Harris Creek reef using the linkage disequilibrium (LD) method (Waples and Do 2008) implemented in NeEstimator v2.01 (Do et al. 2014; minor allele frequencies $<0.05$ excluded). For this analysis, if there were multiple adult broodstock groups from the same reef/population, they were pooled within population (i.e., Sandy Hill 1, 2, and 3 were combined into a single Sandy Hill population; see Table 3). Finally, all wild broodstock source populations were also combined into a single population for an overall wild Choptank River $N_{\mathrm{e}}$ estimate. Although the mixed-age adult samples can be used to estimate $N_{\mathrm{e}}$ (Waples et al. 2014), the offspring cohorts, which represent a single age-class, were used to estimate $N_{\mathrm{b}}$ (Waples 2005). To obtain offspring $N_{\mathrm{e}}$ estimates, raw offspring $N_{\mathrm{b}}$ estimates (LD method) were adjusted according to Waples et al. (2014) using three lifehistory traits: adult life span $=15$ (10-20 years in undisturbed populations, Powell and Cummins 1985), age at maturity $(\alpha)=2$ (averaged values from Galtsoff 1964; Rothschild et al. 1994; Powell et al. 2013), and variation in age-specific fecundity CVf $=0.65$ (from Mroch et al. 2012; Mann et al. 2014).

To examine the extent of genetic differentiation among the broodstock sources, hatchery-produced offspring, and restored Harris Creek sample, $F_{\mathrm{ST}}$ (Nei's $G_{\mathrm{ST}}$; Nei 1973) was calculated in GenoDive. Heterogeneity in allelic frequencies between pairs of samples was tested in GenoDive (G-test; 9999 permutations). Significance criteria were adjusted for the number of simultaneous tests using sequential Bonferroni corrections (Rice 1989). $F_{\mathrm{ST}}$ values (Weir 1996) were recalculated in FreeNA using the 'excluding null alleles' method (Chapuis and Estoup 2007) to correct the positive bias induced by the presence of null alleles on $F_{\mathrm{ST}}$ estimation. Finally, population structure was assessed among broodstock population sources and their offspring, with discriminant analysis of principle components (DAPC) in the R package 'Adegenet' (Jombart 2008).

\section{Results}

\section{Genotyping results and null alleles}

Across the nine cohorts examined, a total of 1299 individuals were genotyped, 846 (141 parents, 705 offspring) of which comprised the mass-spawns and 405 (45 parents, 360 offspring) of which comprised the controlled-spawns (Table 1). A total of 12547 genotypes were scored with an average error rate of $1.9 \%$ across all samples. One locus (Cvi6) was excluded from cohort M6 because of inconsistencies with allele scoring. Null alleles were detected in five (RUCV3, RUCV114, Cvi2i23, Cvi2i4, and Cvi6) out of the nine loci (Table S1), which is consistent with previous studies using the same markers (Rose et al. 2006; Arnaldi et al. 2018). Five out of the nine microsatellite loci showed Hardy-Weinberg disequilibrium with an excess of homozygotes in most of the studied populations (Supplementary Table S1). All population genetic analyses were performed with and without these loci and the two data sets provided similar results. 
Parentage results, variance in reproductive success, and changes in diversity

Parentage assignment of offspring to parental pairs in CERVUS ranged from 74 to $89 \%$ (mean $83.2 \%$ ) at the $95 \%$ confidence cutoff level (Supplementary Table S2). We observed no difference in assignment success between mass- and controlled-spawns (Wilcoxon signed-rank test; $P>0.05)$. Parentage assignment results were then used to assess variance in reproductive success and skew among parents within mass-spawned and controlled-spawn cohorts.

For the mass-spawned cohorts, reproductive success varied widely among individuals - individual males produced $0-58.1 \%$ of assigned offspring (mean $=8.7 \%$, mode $=5 \%$ ) and individual females produced $0-32.6 \%$ of assigned offspring (mean $=8.3 \%$, mode $=0 \%$ ). The standardized variance in reproductive success was higher in males than females in all mass-spawned cohorts (64\% higher mean $V_{\mathrm{k}}$ compared with females; F-test, $\mathrm{F}_{0.05,(5,5)}=$ $0.143, P=0.03$; Fig. 2). Among individuals that were observed to have spawned, $5.8 \%$ of males and $5.6 \%$ of females effectively produced no offspring (averaged over all six cohorts). Male reproductive contribution differed significantly from the expectation of equal contribution, indicating evidence of significant reproductive skew in all six mass-spawns (Supplementary Figure S1). Female reproductive contribution was also highly variable and differed significantly from the expectation of equality in five of the six mass-spawned cohorts; however, the skew was less than that of males (Supplementary Figure S1, i.e., less significant Chi-square deviations). Male reproductive contribution appeared to be affected by male spawning order,

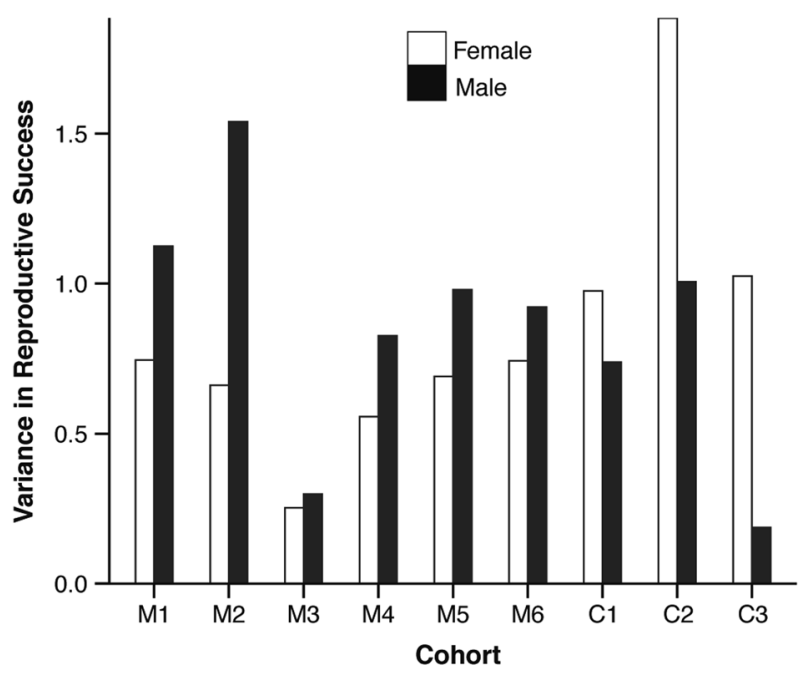

Fig. 2 Standardized variance in reproductive success for males and females across $C$. virginica cohorts. M1-M6 correspond to the massspawned cohorts; M6 corresponds to the LoLA aquaculture line, and C1-C3 correspond to the controlled-spawn cohorts and males that spawned later contributed more offspring $(P=0.03$, Supplementary Figure S2). Overall, high variance in reproductive success among parents resulted in a substantial reduction in $N_{\mathrm{bI}}$ (average $45 \%$ ) and relatively low $N_{\mathrm{bI}} / \mathrm{N}$ ratios (Table 2). $N_{\mathrm{b}}$ estimates varied depending on the method used, but all $N_{\mathrm{bS}}$ estimates were lower than $N_{\mathrm{bI}}\left(N_{\mathrm{bI}}\right.$ ranged from 7.62 to 17.58 , whereas $N_{\mathrm{bS}}$ ranged from 4.13 to 9.85 ; Table 2). The magnitude of reduction in $N_{\mathrm{bI}}$ appeared to be affected by the sex ratios of each cohort, with a marginally significant trend $(P=0.09$, compared with alpha $=0.05$ ) of decreasing variance for sex ratios closer to one (Table 2). For example, the highest (0.84) $N_{b l} \mathrm{I}$ ratio was observed in cohort $\mathrm{M} 3$, where the sex ratios were closest to one, whereas the lowest $(0.36) N_{b 1} / \mathrm{N}$ ratio was observed in cohort $\mathrm{M} 2$, where the sex ratios were farthest from one (0.4). Finally, statistically significant reductions in allelic richness $\left(A_{\mathrm{r}}\right)$ from parents to offspring were found in all the mass-spawned cohorts (Wilcoxon signed-rank test $P<0.03$, Table 2), while reductions in $H_{\mathrm{o}}$ between parents and offspring were not significant $(P>$ 0.05 , Table 2). Results for the controlled-spawns were generally similar to the mass-spawns with high variance in reproductive success among individuals. Individual males produced $3.3-42.5 \%$ of offspring (average $=12.5 \%$, mode $=3.26 \%$ ), whereas individual females produced $0-57.5 \%$ of offspring (average $=14.3 \%$, mode $=1.1 \%$ ). Patterns of $V_{\mathrm{k}}$ between males and females followed the opposite trend of the mass-spawns, with higher variance for females compared with males $(65 \%$ higher than males; Ftest, $\mathrm{F}_{0.05,(2,2)}=0.375, P>0.05$; Fig. 2). Among individuals that were observed to have spawned, $100 \%$ of males had offspring assigned to them vs. $95.2 \%$ of females, both of which are higher than in the mass-spawned cohorts. Again, the high $V_{\mathrm{k}}$ among parents led to a reduction in $N_{\mathrm{bI}}$ (average $=47 \%$ ) and relatively low $N_{\mathrm{bI}} / \mathrm{N}$ ratios (Table 2 ). $N_{\text {bS }}$ was lower than $N_{\text {bI }}$ in all controlled-spawned cohorts (Table 2). We focus on $N_{\mathrm{bI}}$ for the remainder of the study because it can directly be compared with the initial number of spawning adults. Statistically significant reductions in $A_{r}$ between parents and offspring were found in all the controlled-spawn cohorts (Wilcoxon signed-rank test $P<$ 0.03 , Table 2), whereas $H_{\mathrm{o}}$ was maintained in the offspring of cohorts $\mathrm{C} 1$ and $\mathrm{C} 3$ and increased in the offspring of cohort C3 $(P>0.05$, Table 2).

Global relatedness was higher in all hatchery-produced offspring (Supplementary Figure S3; average increase $=$ 0.065). Relatedness in wild broodstock sources ranged from 0.002 to 0.011 , whereas the mean relatedness of wild hatchery-produced offspring ranged from 0.03 to 0.129 . As expected, relatedness in LoLA broodstock parents (0.117) was higher than wild broodstock sources and also increased in the hatchery-produced offspring (0.208). Offspring from the controlled-spawned cohort broodstock source (TB) had 
Table 2 Summary of genetic diversity results for parents and offspring of each $C$. virginica cohort
Table $3 F_{\mathrm{ST}}$ estimates between all $C$. virginica wild and broodstock source populations (below diagonal) and G-test $P$ value (above diagonal)

\begin{tabular}{|c|c|c|c|c|c|c|c|c|}
\hline Cohort & Type & $\mathrm{A}_{\mathrm{r}} \pm$ s.e. & $P$ value $^{1}$ & $H_{\mathrm{o}} \pm$ s.e. & $P$ value $^{2}$ & $\mathrm{~N}_{\mathrm{bI}}$ & $N_{\mathrm{bl}} / \mathrm{N}$ & $N_{\mathrm{bS}}$ \\
\hline \multirow[t]{2}{*}{ M1 } & Adult & $12.56 \pm 2.04$ & $0.007 *$ & $0.67 \pm 0.06$ & 0.36 & 9.99 & 0.43 & 9.85 \\
\hline & Offspring & $8.46 \pm 1.16$ & & $0.55 \pm 0.06$ & & & & \\
\hline \multirow[t]{2}{*}{ M2 } & Adult & $11.71 \pm 1.64$ & $0.007 *$ & $0.58 \pm 0.03$ & 1 & 7.62 & 0.36 & 4.37 \\
\hline & Offspring & $6.69 \pm 0.81$ & & $0.55 \pm 0.03$ & & & & \\
\hline \multirow[t]{2}{*}{ M3 } & Adult & $11.57 \pm 1.76$ & $0.007^{*}$ & $0.68 \pm 0.06$ & 0.09 & 17.58 & 0.84 & 4.13 \\
\hline & Offspring & $8.36 \pm 1.22$ & & $0.54 \pm 0.07$ & & & & \\
\hline \multirow[t]{2}{*}{ M4 } & Adult & $12.11 \pm 2.26$ & $0.007 *$ & $0.65 \pm 0.09$ & 0.46 & 13.63 & 0.62 & 9.32 \\
\hline & Offspring & $7.26 \pm 1.23$ & & $0.58 \pm 0.10$ & & & & \\
\hline \multirow[t]{2}{*}{ M5 } & Adult & $14.38 \pm 2.84$ & $0.012 *$ & $0.63 \pm 0.09$ & 0.09 & 17.8 & 0.52 & 4.57 \\
\hline & Offspring & $10.11 \pm 1.63$ & & $0.52 \pm 0.10$ & & & & \\
\hline \multirow[t]{2}{*}{ M6 } & Adult & $8.56 \pm 1.31$ & $0.007 *$ & $0.68 \pm 0.08$ & 0.08 & 11.29 & 0.56 & 6.03 \\
\hline & Offspring & $6.01 \pm 0.75$ & & $0.44 \pm 0.10$ & & & & \\
\hline \multirow[t]{2}{*}{$\mathrm{C} 1$} & Adult & $11 \pm 2.62$ & $0.031 *$ & $0.58 \pm 0.10$ & 1 & 8.19 & 0.55 & 4.04 \\
\hline & Offspring & $7.33 \pm 1.57$ & & $0.58 \pm 0.11$ & & & & \\
\hline \multirow[t]{2}{*}{$\mathrm{C} 2$} & Adult & $9.33 \pm 1.94$ & $0.031^{*}$ & $0.51 \pm 0.09$ & 1 & 6.11 & 0.41 & 4.05 \\
\hline & Offspring & $5.95 \pm 1.01$ & & $0.51 \pm 0.11$ & & & & \\
\hline \multirow[t]{2}{*}{$\mathrm{C} 3$} & Adult & $11.16 \pm 2.70$ & $0.031 *$ & $0.56 \pm 0.10$ & 0.47 & 9.38 & 0.63 & 4.74 \\
\hline & Offspring & $7.41 \pm 1.64$ & & $0.60 \pm 0.11$ & & & & \\
\hline $\mathrm{HC}$ & - & $14.19 \pm 2.45$ & - & $0.59 \pm 0.08$ & - & - & - & \\
\hline
\end{tabular}

$P$ values from Wilcoxon signed-rank tests after Benjamini and Hochberg correction: Ar, allelic richness ${ }^{1}$ or $H_{o}$, observed heterozygosity ${ }^{2}$ between parents and offspring. $N_{\mathrm{bI}} / \mathrm{N}$ represents the ratio of number of breeders from Christie et al. (2012) to the number of broodstock spawned and $N_{\mathrm{bS}}$ represents $N_{\mathrm{b}}$ based on sibship reconstruction from Waples and Waples (2011). HC represents the restored Harris Creek sample. M1-M6 represent the mass-spawned cohorts; $\mathrm{C} 1-\mathrm{C} 3$ represent the controlled-spawned cohorts

\begin{tabular}{|c|c|c|c|c|c|c|c|}
\hline & BBY & CLP & $\mathrm{HC}$ & LoLA & SH1 & $\mathrm{SH} 2$ & $\mathrm{SH} 3$ \\
\hline BBY & - & 0.556 & 0.193 & $<0.001$ & 0.012 & 0.013 & 0.18 \\
\hline CLP & 0.009 & - & 0.283 & $<0.001$ & 0.036 & 0.005 & 0.061 \\
\hline $\mathrm{HC}$ & -0.001 & 0.004 & - & $<0.001$ & 0.353 & $<0.001$ & 0.016 \\
\hline LoLa & 0.056 & 0.054 & 0.058 & - & $<0.001$ & $<0.001$ & $<0.001$ \\
\hline SH1 & 0.022 & 0.017 & 0.007 & 0.079 & - & 0.05 & 0.306 \\
\hline SH2 & 0.021 & 0.02 & 0.019 & 0.077 & 0.011 & - & 0.001 \\
\hline SH3 & 0.016 & 0.012 & 0.009 & 0.06 & -0.001 & 0.018 & - \\
\hline
\end{tabular}

Bonferroni correction is given in bold $(P<0.002)$. Population codes are explained in Table 1 or Fig. 1; HC represents the restored Harris Creek sample the smallest relative increase in relatedness (0.028), whereas offspring within Chlora Point (CLP; mass-spawned cohort) exhibited the greatest relative increase in relatedness (0.118). Relatedness in the Harris Creek restored sample was comparable to that in wild broodstock sources and was relatively low overall (0.012).

\section{Genetic diversity and differentiation among wild broodstock and restored oysters}

Genetic diversity $\left(\mathrm{A}_{\mathrm{r}}\right.$ and $\left.H_{\mathrm{o}}\right)$ of wild adult broodstock ranged from 9.33 to 14.38 and 0.51 to 0.68 , respectively (Table 2). The LoLA (aquaculture) adults displayed the lowest allelic richness overall (8.56; Table 2), but had comparable levels of heterozygosity (0.68). Overall, the restored Harris Creek sample had the second highest allelic richness (14.19) and comparable levels of heterozygosity $(0.59)$ to wild broodstock populations. Pairwise $F_{\mathrm{ST}}$ analyses (Nei's $G_{\mathrm{ST}}$ ) revealed low genetic differentiation among most broodstock sources. All pairwise $F_{\mathrm{ST}}$ estimates between wild broodstock source populations were small, ranging from -0.001 to 0.022 (Table 3) -none were significant after Bonferonni correction. Recalculating $F_{\text {ST }}$ excluding null alleles in FreeNA produced very similar estimates to un-corrected values (Supplementary Table S4). Pairwise $F_{\mathrm{ST}}$ estimates between the Harris Creek and wild broodstock source populations were small and non-significant, ranging from -0.001 to 0.019 (Table 3). Pairwise $F_{\mathrm{ST}}$ estimates between the LoLA broodstock adults and Chesapeake Bay wild populations were higher, ranging from 0.054 to 0.079 , and all comparisons (adult broodstock: BBY, CLP, HC, TB, SH1, SH2, and SH3) were statistically 


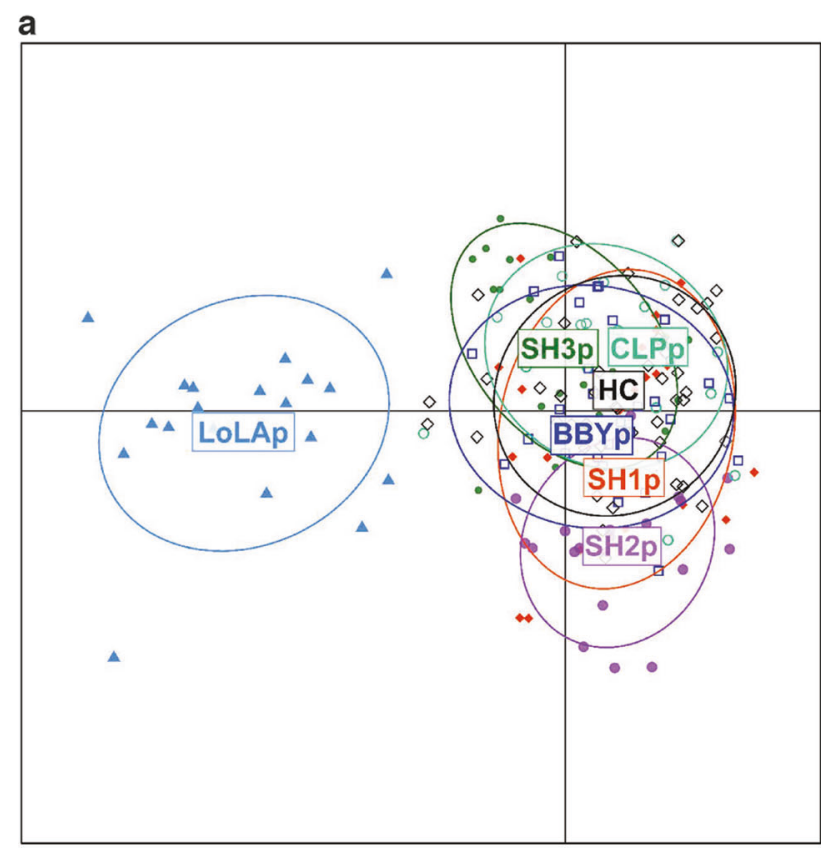

Fig. 3 Discriminant analysis of principle components (DAPC) among wild and restored $C$. virginica populations. Results are shown for adult samples (broodstock and restored populations) only a and for all individuals (adults and offspring $\mathbf{b}$. Number of PCs to retain for each

significant (G-test $P<0.001)$. Interestingly, pairwise $F_{\mathrm{ST}}$ estimates between hatchery-produced offspring (i.e. the cohorts produced from wild broodstock) and wild broodstock parent sources were typically higher than comparisons among only adult broodstock $\left(0.011<F_{\mathrm{ST}}<0.148\right.$; Supplementary Table S5). Similar to the $F_{\text {ST }}$ results, analyses of population structure via DAPC revealed two or three major clusters, with LoLA broodstock adults (and offspring) grouping distinctly from Choptank River wild broodstock and the restored Harris Creek sample (Figs. 3a, b). More structure was evident among the offspring cohorts (e.g., SH2 and SH1 vs. SH3; Supplementary Figure S4), and broodstock sources and offspring tended to group together, as expected (Fig. 3a). More subtle genetic differences were observed between Sandy Hill ( $\mathrm{SH}$ ) broodstock samples (e.g., SH2 adults vs. others) despite being sampled from a common population (Fig. 3b). The Harris Creek sample clustered in the center of the five other wild Choptank River broodstock sources (Fig. 3b).

\section{Effective population sizes of wild broodstock sources and the Harris Creek population}

Contemporary effective population size $\left(N_{\mathrm{e}}\right)$ estimates varied among the different wild (broodstock source) populations but were fairly consistent overall, ranging from 75.3 to 129.6 with a mean of 102 . Most of the estimates were bounded at the $95 \%$ confidence limits $(95 \%$ confidence

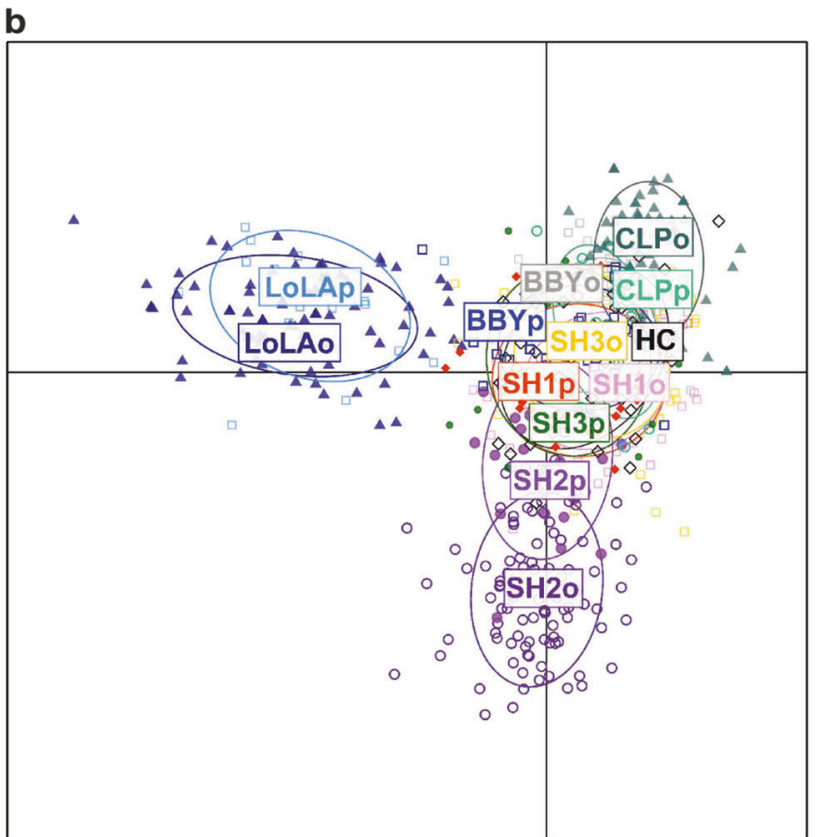

set of analyses was determined via the a-spline optimization approach in Adegenet (29, and 23 PCs retained for all, and parents only, respectively). Letters at the end of population names/codes represent parent $(\mathrm{p})$ or offspring (o) groups

Table 4 Effective population sizes (and confidence intervals (CIs)) of wild, hatchery-produced and restored $C$. virginica populations based on the linkage disequilibrium method (Waples and Do 2008)

\begin{tabular}{|c|c|c|c|c|c|c|}
\hline & \multicolumn{3}{|c|}{ Parents } & \multicolumn{3}{|c|}{ Offspring } \\
\hline & $N$ & $N_{\mathrm{e}}$ & $\mathrm{CI}$ & $\mathrm{N}$ & $N_{\mathrm{e}}^{\mathrm{a}}$ & $\mathrm{CI}^{\mathrm{a}}$ \\
\hline \multicolumn{7}{|c|}{ Restored population } \\
\hline Harris Creek & 48 & 68.3 & $(41.6,148.6)$ & - & - & - \\
\hline \multicolumn{7}{|c|}{ Aquaculture line } \\
\hline LoLA & 20 & 31.1 & $(18.6,69.9)$ & 92 & 10.5 & $(8.4,13)$ \\
\hline \multicolumn{7}{|c|}{ Wild populations } \\
\hline Black Buoy & 34 & 129.6 & $(52.1, \infty)$ & 102 & 21.9 & $(18,26.6)$ \\
\hline Chlora Point & 22 & $\infty$ & $(86, \infty)$ & 98 & 4.8 & $(3.8,6.6)$ \\
\hline Sandy Hill & 65 & 75.3 & $(54.7,119.2)$ & 298 & 22.3 & $(19.7,25)$ \\
\hline Pooled & 166 & 178.2 & $(126.2,281)$ & 781 & 36.7 & $(33.3,40.6)$ \\
\hline
\end{tabular}

$N_{\mathrm{e}}^{\mathrm{a}} \mathrm{CI}^{\mathrm{a}}$ represent adjusted $N_{\mathrm{e}}$ and CIs of hatchery-produced offspring according to Waples et al. (2014)

interval range 52.1-119.2; Table 4). Two $N_{\mathrm{e}}$ estimates were unbounded-Black Buoy and Chlora Point, but these had relatively small sample sizes $(N=34$ and $N=22$, respectively). The $N_{\mathrm{e}}$ estimate for the pooled wild broodstock sources was highest at 366.8 and had the largest $95 \%$ confidence interval range (200.1-1424.3). The $N_{\mathrm{e}}$ estimate for the Harris Creek sample was similar to the range of values estimated for wild populations at 68.3 - confidence limits for the wild populations and the restored sample 
overlapped substantially (Table 4$)$. As expected, $N_{\mathrm{e}}$ estimates were systematically higher in wild populations compared to the representative aquaculture line (LoLA), and effective sizes were systematically higher in wild broodstock parents compared to their hatchery-reared offspring (Table 4).

\section{Discussion}

\section{Changes in genetic diversity resulting from hatchery propagation and spawning protocol}

Across all hatchery-produced cohorts of oysters (mass- and controlled-spawns), offspring displayed lower genetic diversity, higher global relatedness, and reduced $N_{\mathrm{b}}$ and $N_{\mathrm{e}}$ compared with their wild adult progenitors. The reduction in $N_{\mathrm{b}}$ was the most substantial among the diversity metrics examined, reflecting the high variance in reproductive success observed among parents. As expected, patterns of diversity loss differed between the two spawning protocols, but the controlled-spawns did not reduce overall reproductive variance (see below). Indeed, controlled fertilizations of oysters may not necessarily reduce diversity loss during hatchery cultivation. For example, Boudry et al. (2002) found high $V_{\mathrm{k}}$ of cohorts of Pacific oysters despite controlled fertilizations. Post-spawning genotype-dependent larval mortality may also contribute to high $V_{\mathrm{k}}$ among parents (e.g., Plough 2016; Plough 2018).

In the mass-spawned cohorts, where we expected $V_{\mathrm{k}}$ to be greatest, we observed higher skew in males compared with females, which is consistent with results from previous studies of fish and shellfish (e.g., Bekkevold et al. 2002; Boudry et al. 2002). The high male variance can possibly be explained by differences in sperm quality or quantity among males in the competitive, pooled fertilization environment of a mass-spawn. Sperm competition can influence the proportion of eggs fertilized and differences in sperm traits (quality), such as sperm motility and velocity, can lead to variable contributions among males (Gaffney et al. 1993; Withler and Beacham 1994; Wedekind et al. 2007). However, male reproductive variance may not be attributed to sperm traits alone (e.g., Linhart et al. 2005; Kaspar et al. 2007). Fertilization rates may also depend on gametic compatibility (e.g., Gaffney et al. 1993), which was not tested in this study. Other characteristics of the mass-spawn protocol, such as the timing of gamete release, may also lead to imbalanced reproductive contributions. For example, we found that males that released gametes later in the massspawns contributed more offspring (Supplementary Figure S2). Fertilizing with pooled sperm from natural spawns is a common practice in shellfish restoration hatcheries (e.g., in Maryland, HPL Oyster Hatchery; in Martha's Vineyard,
Massachusetts, Emma Green-Beach, Martha's Vineyard Shellfish Group Inc., personal communication; and in New York Harbor, Rebecca Resner, Billion Oyster Project, personal communication), but the inability to control the timing of gamete release or gamete output may increase variance in reproductive success among parents.

In contrast to the mass-spawn results, the controlledspawns effectively reduced male reproductive variance, but increased female reproductive variance, resulting in a similar reduction in $N_{\mathrm{b}}$ (low ratios of $N_{\mathrm{b}} / \mathrm{N}$ ), and effectively negating any benefits from reducing the male variance component. The inadvertent increase in female variance likely resulted from several factors associated with the controlled-spawning design, which relied on natural spawns within self-contained vessels. First, the number of eggs per female was not normalized across individuals before fertilization (they were pooled and then divided evenly); thus, differences in fecundity or effective fecundity among females could have contributed to female reproductive variance. Second, egg quality or viability may have varied among females, with reduced egg viability at the time of fertilization for females that spawned earlier compared with females that spawned closer to the time of time of fertilization. Eggs from some females were not fertilized for $2.5 \mathrm{~h}$ after the first observation of spawning (see Supplementary Table S7 for detailed information on timing of gamete release), and thus, they may have been less viable at the time of fertilization. Though we lack detailed information on temporal changes to gamete viability in $C$. virginica, an experimental study of gamete viability in the broadcast spawning bivalve Cerastoderma edule showed that percent fertilization decreased $50 \%$ after $2 \mathrm{~h}$ (André and Lindegarth 1995), indicating that a 2.5 -hour window could reduce fertilization success during spawning. Natural spawning protocols are clearly less ideal than directed fertilizations via strip-spawning of adults. However, the goal of these experiments was to control fertilizations (and sperm competition) within the framework of typical HPL Oyster Hatchery protocols that use natural spawning for oyster restoration. Employing strip-spawning would make large numbers of pairwise fertilizations logistically easier, but this is not always preferred or possible, especially if programs are broodstock limited, and differential survival of larvae can still result in skewed contributions and high $V_{\mathrm{k}}$ among parents (Boudry et al. 2002; Lallias et al. 2010). Overall, natural, individual spawns are challenging to execute on a small-scale, and thus, this practice is not likely to be viable for large-scale restoration hatcheries. Overcoming large variance in family sizes remains a major obstacle towards maximizing genetic diversity and $N_{\mathrm{e}}$ in hatchery-propagated individuals for restoration. The findings from this study, that there is an average loss of $\sim 45 \%$ of the $N_{\mathrm{b}}$ between parents and offspring in the mass-spawns, could help to 
inform decisions about spawning practices and the number of broodstock used for eastern oyster or other shellfish restoration programs.

\section{Genetic differentiation between wild, hatchery- produced, and restored oysters}

Wild broodstock source populations within the Choptank River showed no genetic differentiation, which is consistent with previous studies reporting high gene flow among oyster populations in Chesapeake Bay (e.g., Rose et al. 2006) and Delaware Bay (He et al. 2012). Despite low $F_{\mathrm{ST}}$ values overall, Rose et al. (2006) observed a weak pattern of isolation by distance among oyster populations in Chesapeake Bay, indicating some barriers to gene flow over $100 \mathrm{~s}$ of $\mathrm{km}$. High gene flow among mid-Bay populations may also be driven by a long history of human-mediated adult and juvenile oyster movement, planting, and transplantation throughout the Chesapeake Bay (Kennedy and Breisch 1983; Mann and Powell 2007). Wild Choptank River and restored Harris Creek reef oysters differed genetically (statistically significant pairwise $F_{\mathrm{ST}}$ ) from the LoLA aquaculture line, which is expected for a selectively bred, "closed" hatchery line that was developed with genetically divergent wild progenitors from Louisiana (Appleyard and Ward 2006; Aquaculture Genetics and Breeding Technology Center 2009; Champagnon et al. 2012). Finally, the restored Harris Creek oyster population showed no genetic differentiation from the local broodstock populations (e.g., Table 3 and Fig. 3), which is consistent with the fact that these local populations were used to produce oysters that are planted in Harris Creek. However, the power provided by eight microsatellite markers is unlikely to be sufficient to resolve fine-scale population structure among reefs or restored populations over such a small geographic scale.

\section{Comparisons of contemporary effective population sizes between wild and restored reefs}

Contemporary $N_{\mathrm{e}}$ estimates in this study agree generally with the magnitude of values reported for eastern oyster populations in the Delaware Bay (37-437) by $\mathrm{He}$ et al. (2012), but are lower than those reported for the James River (535-1 516) by Rose et al. (2006), and higher than that reported for the Delaware Bay (33.8) by Hedgecock et al. (1992). Although there is a rather wide range of $N_{\mathrm{e}}$ estimates reported across locations, most estimates are fairly low $(<1000) . N_{\mathrm{e}}$ estimates for two of the broodstock sources in this study were unbounded (BBY and CLP; sample sizes $<34$, which is low for $N_{\mathrm{e}}$ estimation via the LD method; Waples and Do 2010), but estimates for the remaining populations were bounded, and thus provide insight into the range of possible $N_{\mathrm{e}}$ for the wild broodstock populations in the Choptank River (75.3-129.6). Compared with estimates for wild oysters in the Choptank River, the restored oyster sample from Harris Creek had similar levels of genetic diversity and effective population size $\left(N_{\mathrm{e}}=\right.$ 68.3), which suggests that the Harris Creek restoration program has not caused significant declines in genetic diversity, at least based on the single reef sampled and metrics examined.

Though we did not detect major declines in diversity for this restoration program, genetic analyses of similar restocking or enhancement efforts in marine fish have yielded mixed results in terms of the severity of associated genetic changes. Although some studies show that stock enhancement produced effectively no change to population genetic diversity (e.g., Heggenes et al. 2006; Gow et al. 2011; Katalinas et al. 2017), other studies have shown rapid declines in diversity and severe Ryman-Laikre effects after only a few generations (Gold et al. 2008; Karlsson et al. 2008; Christie et al. 2012). Disparate results among studies may be driven by specific characteristics of the program (i.e., husbandry practices), the initial status of wild populations, or possibly the design of the monitoring study itself (e.g., number of samples, type and number of markers used). In the current study, a lack of salient genetic decline may reflect specific HPL hatchery broodstock management and spawning practices that are implemented to minimize declines in genetic diversity. For example, the HPL hatchery uses $100-1000 \mathrm{~s}$ of wild broodstock each year while past broodstock are rotated out and retired after 3-4 years of use (Stephanie Alexander, HPL oyster hatchery, personal communication). Moreover, deliberate out-planting of many distinct cohorts of spat (i.e., produced from spawns with different sets of parents), ensures that a given restored reef will comprise multiple spawns, from multiple years, from hundreds of parents. Of course, caution must be exercised when inferring the genetic impact of oyster restoration in Harris Creek based on the sampling of a single restored reef. The analysis of additional restored populations with variable planting histories, and the use of larger marker data sets (e.g., $1000 \mathrm{~s}$ of SNPs) is ongoing and should provide a more conclusive picture of the genetic impacts of hatchery propagation and planting on in these populations.

Effective population size $\left(N_{\mathrm{e}}\right)$ estimates in marine animals tend to be much smaller than the census population size (N) (e.g., Hedrick 2005; Palstra and Ruzzante 2008), and extremely low $N_{\mathrm{e}} / \mathrm{N}$ ratios $\left(10^{-3}-10^{-6}\right)$ have been reported in many marine invertebrates and fishes (Hedgecock 1994; Hauser et al. 2002; Hedrick 2005; Hauser and Carvalho 2008), perhaps suggesting high variation in reproductive contribution among adults. So, how should the $N_{\mathrm{e}}$ estimates of oysters in this and previous studies be considered in a conservation or management context? Applying relatively cautious conservation thresholds (e.g., 
the 50/500 rule; Franklin 1980; Franklin and Frankham $1998), N_{\mathrm{e}}$ estimates of oysters are on the order of magnitude of what is required for inbreeding avoidance, but are less than the prescribed target for preserving long-term evolutionary viability or quantitative genetic variation $\left(N_{\mathrm{e}}>500\right)$. However, concerns about the genetic risks for populations with small $N_{\mathrm{e}}$ may be slightly overblown if there is frequent gene flow (i.e. replenishing genetic variation despite low $N_{\mathrm{e}}$ ), which is typical for populations of marine animals like oysters that have a highly dispersive larval stage (e.g., Gaffney 2006; Hauser and Carvahlo 2008; Palstra and Ruzzante 2008).

Although low $N_{\mathrm{e}}$ estimates may overstate the level of genetic risk to some marine populations, it has also been argued that estimates of $N_{\mathrm{e}} / \mathrm{N}$ ratios in marine species may be artificially low (downwardly biased) when true $N_{\mathrm{e}}$ is actually quite high (Palstra and Ruzzante 2008; Waples 2016). Using simulations, Waples (2016) examined the range of life-history characteristics (e.g., longevity, age at maturity, fecundity, and variance in reproductive success that increase with age) that would be required to generate tiny $N_{\mathrm{e}} / \mathrm{N}$ ratios (e.g., $<0.001$ ) observed in empirical studies of fish and shellfish, and determined that unless very large sample sizes were used (e.g., $10 \mathrm{~s}$ of thousands), $N_{\mathrm{e}}$ estimates could be seriously biased. This does not mean that all low $N_{\mathrm{e}}$ estimates are wrong, but that we should be very cautious about the interpretation of the $N_{\mathrm{e}}$ estimates in this and previous studies using relatively few markers and small sample sizes. If estimates across samples or markers are bimodal in distribution (very low and high) and/or are typically unbounded, a very large $N_{\mathrm{e}}$ cannot be rejected out of hand. Given that the $N_{\mathrm{e}}$ estimates in this study are generally consistent with previous $N_{\mathrm{e}}$ estimates of oyster populations in the Chesapeake Bay (and most estimates were bounded), it seems likely that they are reflective of truly low $N_{\mathrm{e}}$ for populations in the Choptank River.

\section{Conclusions}

This study provides an initial examination of the genetic impacts of a large-scale eastern oyster restoration program, and the overarching findings are relevant for future eastern oyster restoration programs as well as for the restoration of other marine shellfish with similar life-history features. Overall, hatchery-based propagation of oysters led to substantial reductions in diversity and the $N_{\mathrm{b}}$ from parents to offspring (a decline of $\sim 45 \%$ in $N_{\mathrm{b}}$ on average), which can be explained by the high variance in reproductive success $\left(V_{\mathrm{k}}\right)$ among adults in mass-spawns and hatchery-based larval culture. Experiments employing controlled, natural spawn protocols with independent fertilizations of pooled eggs failed to reduce $V_{\mathrm{k}}$ compared with mass-spawns.
Despite high $V_{\mathrm{k}}$ and diversity loss in the offspring of individuals cohorts, estimates of genetic diversity metrics and $N_{\mathrm{e}}$ from field-based samples did not indicate major losses of genetic diversity in hatchery-planted oysters in Harris Creek, MD, at least based on the single restored population examined. Additional restored populations will need to be analyzed before any definitive conclusions can be made about the genetic impact of this restoration program. The use of a large number of rotated, wild broodstock, from which mixed larval batches are planted and re-planted over time may have helped to minimize diversity loss within restored reef sites. Based on the results of this study, a number of standard recommendations could be made for oyster (or other shellfish) restoration programs, including using large numbers of rotated, wild broodstock, and implementing pair-cross matings (Camara and Vadopalas 2009). However, pair-cross matings and/or strip-spawning may not be feasible for some restoration programs, especially those that employ mass-spawns or are broodstock limited.

\section{Data archiving}

Genotype data available from the Dryad Digital Repository: https://doi.org/10.5061/dryad.h3kv180.

Acknowledgements We thank the HPL Oyster Hatchery for their help with spawns, broodstock conditioning, and larval/juvenile culturing, Anna Priester for assistance with hatchery work, Scott Bingham and ASU DNA Laboratory for microsatellite sequencing, and Kennedy Paynter for Harris Creek sample collection. We also thank Katherine McFarland for helpful comments on previous versions of the manuscript. Support for this work was provided by the Deerbrook Charitable Trust (DCT 15-30 to LVP), Maryland Sea Grant (5-230360 to $\mathrm{KMH}$ and LVP), and the University of Maryland Center for Environmental Science.

\section{Compliance with ethical standards}

Conflict of interest The authors declare that they have no conflict of interest.

Publisher's note: Springer Nature remains neutral with regard to jurisdictional claims in published maps and institutional affiliations.

\section{References}

Aquaculture Genetics and Breeding Technology Center (ABC) (2009) The aquaculture genetics and breeding technology's oyster breeding programme. Virginia Institute of Marine Science, Gloucester Point, VA, p 28

Allendorf FW, Ryman N (1987) Genetic management of hatchery stocks. In: Ryman N, Utter F (eds) Population genetics and fishery management. The Blackburn Press, Caldwell, NJ, p 141-159

André C, Lindegarth M (1995) Fertilization efficiency and gamete viability of a sessile, free-spawning bivalve, Cerastoderma edule. Ophelia 43:215-277 
Appleyard SA, Ward RD (2006) Genetic diversity and effective population size in mass selection lines of Pacific oyster (Crassostrea gigas). Aquaculture 254:148-159

Araki H, Cooper B, Blouin MS (2007) Genetic effects of captive breeding cause a rapid, cumulative fitness decline in the wild. Science 318:100-103

Araki H, Berejikian BA, Ford MJ, Blouin MS (2008) Fitness of hatchery-reared salmonids in the wild. Evol Appl 1:342-355

Arnaldi KG, Walters LJ, Hoffman EA (2018) Effects of time and harvest on genetic diversity of natural and restored oyster reefs. Restor Ecol 26:943-951

Beck MW, Brumbaugh RD, Airoldi L, Carranza A, Coen LD, Crawford C et al. (2011) Oyster reefs at risk and recommendations for conservation, restoration, and management. BioScience 61:107-116

Bekkevold D, Hansen MM, Loeschcke V (2002) Male reproductive competition in spawning aggregations of cod (Gadus morhua, L.). Mol Ecol 1:91-102

Bell JD, Leber KM, Blankenship HL, Loneragan NR, Masuda R (2008) A new era for restocking, stock enhancement and sea ranching of coastal fisheries resources. Rev Fish Sci 16:1-9

Benjamini Y, Hochberg Y (1995) Controlling the false discovery rate: a practical and powerful approach to multiple testing. J R Stat Sci 57:289-300

Blankenship HLEE, Leber KM (1995) A responsible approach to marine stock enhancement. Am Fish Soc Sym 15:167-175

Boudry P, Collet B, Cornette F, Hervouet V, Bonhomme F (2002) High variance in reproductive success of the Pacific oyster (Crassostrea gigas, Tunberg) revealed by microsatellite-based patentage analysis of multifactorial crosses. Aquaculture 204:283-296

Brown BL, Franklin DE, Gaffney PM, Hong M, Dendanto D, Kornfield I (2000) Characterization of microsatellite loci in the Eastern oyster, Crassostrea virginica. Mol Ecol 9:2217-2219

Brumbaugh RD, Coen LD (2009) Contemporary approaches for smallscale oyster reef restoration to address substrate versus recruitment limitation: a review and comments relevant for the Olympia oyster, Ostrea lurida Carpenter 1864. J Shellfish Res 28:147-161

Camara MD, Vadopalas B (2009) Genetic aspects of restoring Olympia oysters and other native bivalves: balancing the need for action, good intentions, and the risks of making things worse. J Shellfish Res 28:121-145

Carlsson J, Reece KS (2007) Eight PCR primers to amplify ESTlinked microsatellites in the Eastern oyster, Crassostrea virginica genome: Primer note. Mol Ecol Notes 7:257-259

Caughley G, Gunn A (1996) Conservation biology in theory and practice. Blackwell Science, Cambridge, MA, USA

Champagnon J, Elmberg J, Guillemain M, Gauthier-Clerc M, Lebreton JD (2012) Conspecifics can be aliens too: a review of effects of restocking practices in vertebrates. J Nat Conserv 20:231-241

Chapuis MP, Estoup A (2007) Microsatellite null alleles and estimation of population differentiation. Mol Biol Evol 24:621-631

Christie MR, Marine ML, French Ra, Waples RS, Blouin MS (2012) Effective size of a wild salmonid population is greatly reduced by hatchery supplementation. Heredity 109:254-260

Dinnel PA, Peabody B, Peter-Contesse T (2009) Rebuilding Olympia oysters, Ostrea lurida Carpenter 1864, in Fidalgo Bay, Washington. J Shellfish Res 28:79-85

Do C, Waples RS, Peel D, Macbeth GM, Tillett BJ, Ovenden JR (2014) NeEstimatorv2: Re-implementation of software for the estimation of contemporary effective population size $(\mathrm{Ne})$ from genetic data. Mol Res 14:209-214

Frankham R (2008) Genetic adaptation to captivity. Mol Ecol $17: 325-333$

Frankham R, Ballou J, Briscoe D (2010) Introduction to conservation genetics. Cambridge University Press, Cambridge, UK, p 261
Franklin IR (1980) Evolutionary change in small populations. In: Soule ME, Wilcox BA (eds). Conservation Biology: An Evolutionary Ecological Perspective. Sinauer Associates, Massachusetts, p 135-140

Franklin IR, Frankham R (1998) How large must populations be to retain evolutionary potential? Anim Conserv 1:69-73

Gaffney PM (2006) The role of genetics in shellfish restoration. Aquat Living Resour 19:277-282

Gaffney PM, Bernat CM, Allen SK (1993) Gametic incompatibility in wild and cultured populations of the eastern oyster, Crassostrea virginica (Gmelin). Aquaculture 115:273-284

Galtsoff PS (1964) The American oyster, Crassostrea virginica Gmelin. Fish Bull 64:1-480

Gold JR, Ma L, Saillant E, Silva PS, Vega RR (2008) Genetic effective size in populations of hatchery-raised red drum released for stock snhancement. Trans Am Fish Soc 137:1327-1334

Goudet J (2002). FSTAT, a program to estimate and test gene diversities and fixation indices (version 2.9.3). Available from http://www2.unil.ch/popgen/softwares/fstat.htm Updated from Goudet (1995)

Goudet J (2005). HIERFSTAT, a package for R to compute and test hierarchical F-statistics. Mol Ecol Notes. Available at https:// onlinelibrary.wiley.com/doi/abs/10.1111/j.1471-8286.2004. 00828.x

Gow JL, Tamkee P, Heggenes J, Wilson GA, Taylor EB (2011) Little impact of hatchery supplementation that uses native broodstock on the genetic structure and diversity of steelhead trout revealed by a large-scale spatio-temporal microsatellite survey. Evol Appl 4:763-782

Hanley TC, Hughes AR, Williams B, Garland H, Kimbro DL (2016) Effects of intraspecific diversity on survivorship, growth, and recruitment of the eastern oyster across sites. Ecology 97:1518-1529

Hauser L, Adcock GJ, Smith PJ, Bernal Ramirez JH, Carvalho GR (2002) Loss of microsatellite diversity and low effective population size in an overexploited population of New Zealand snapper (Pagrus auratus). Proc Natl Acad Sci USA 18:11742-11747

Hauser L, Carvalho GR (2008) Paradigm shifts in marine fisheries genetics: ugly hypotheses slain by beautiful facts. Fish Fish 9:333-362

He Y, Ford SE, Bushek D, Powell EN, Bao Z, Guo X (2012) Effective population sizes of eastern oyster Crassostrea virginica (Gmelin) populations in Delaware Bay, USA. J Mar Res 70:357-379

Hedgecock D (1994) Does variance in reproductive success limit effective population size of marine organisms? In: Beaumont A (eds) Genetics and evolution of aquatic organisms. Chapman and Hall, London, p 122-134

Hedgecock D, Chow V, Waples RS (1992) Effective population numbers of shellfish broodstocks estimated from temporal variance in allelic frequencies. Aquaculture 108:215-232

Hedgecock D, Pudovkin AI (2011) Sweepstakes reproductive success in highly fecund marine fish and shellfish: a review and commentary. Bull Mar Sci 87:971-1002

Hedrick PW (2005) Large variance in reproductive success and the $\mathrm{Ne} / \mathrm{N}$ ratio. Evolution 438:753-754

Heggenes J, Beere M, Tamkee P, Taylor EB (2006) Genetic diversity in steelhead before and after conservation hatchery operation in a coastal, Boreal River. Trans Am Fish Soc 135:251-267

Holley JR, McComas KA, Hare MP (2018) Troubled waters: Risk perception and the case of oyster restoration in the closed waters of the Hudson-Raritan Estuary. Mar Policy 91:104-112

Jackson JBC, Kirby MX, Berger WH, Bjorndal KA, Botsford LW, Bourque BJ et al. (2001) historical collapse overfishing of and the recent coastal ecosystems. Science 293:629-638 
Jombart T (2008) Adegenet: A R package for the multivariate analysis of genetic markers. Bioinformatics 24:1403-1405

Jones OR, Wang J (2010) COLONY: a program for parentage and sibship inference from multilocus genotype data. Mol Ecol Res 10:551-555

Kalinowski ST, Taper ML, Marshall TC (2007) Revising how the computer program CERVUS accommodates genotyping error increases success in paternity assignment. Mol Ecol 16:1099-1106

Karlsson S, Saillant E, Bumguardner BW, Vega RR, Gold JR (2008) Genetic identification of recovered hatchery-released red drum in Texas bays and estuaries. N Am J Fish Manage 28:1294-1304

Kaspar V, Kohlmann K, Vandeputte M, Rodina M, Gela D, Kocour M et al. (2007) Equalizing sperm concentrations in a common carp (Cyprinus carpio) sperm pool does not affect variance in proportions of larvae sired in competition. Aquaculture 272: S204-S209

Katalinas CJ, Brenkert K, Darden T, Denson MR (2017) A genetic assessment of a red drum, Sciaenops ocellatus, stock enhancement program. J World Aquacult Soc 49:523-539

Kennedy VS, Breisch LL (1983) Sixteen decades of political management of the oyster fishery in Maryland's Chesapeake Bay. J Exp Manage 16:153-171

Kennedy VS, Breitburg DL, Christman MC, Luckenbach MW, Paynter K, Kramer J et al. (2011) Lessons learned from efforts to restore oyster populations in Maryland and Virginia, 1990 to 2007. J Shellfish Res 30:719-731

Laikre L, Schwartz MK, Waples RS, Ryman N (2010) Compromising genetic diversity in the wild: unmonitored large-scale release of plants and animals. Trends Ecol Evolut 25:520-529

Laing I, Walker P, Areal F (2006) Return of the native: is European oyster (Ostrea edulis) stock restoration in the UK feasible? Aquat Living Resour 19:283-287

Lallias D, Taris N, Boudry P, Bonhomme F, Lapégue S (2010) Variance in the reproductive success of flat oyster Ostrea edulis L. assessed by parentage analysis in natural and experimental conditions. Genet Res 92:175-187

Lind CE, Evans BS, Knauer J, Taylor JJU, Jerry DR (2009) Decreased genetic diversity and a reduced effective population size in cultured silver-lipped pearl oysters (Pinctada maxima). Aquaculture 286:12-19

Linhart O, Rodina M, Gela D, Kocour M, Vandeputte M (2005) Spermatozoal competition in common carp (Cyprinus carpio): What is the primary determinant of competition success? Reproduction 130:705-711

Lorenzen K, Beveridge MCM, Mangel M (2012) Cultured fish: Integrative biology and management of domestication and interactions with wild fish. Biol Rev Camb Philos Soc 87:639-660

Lynch M, Ritland K (1999) Estimation of pairwise relatedness with molecular markers. Genetics 152:1753-1766

Mann R, Powell EN (2007) Why oyster restoration goals in the Chesapeake Bay are not and probably cannot be achieved. J Shellfish Res 26:905-917

Mann R, Southworth M, Carnegie RB, Crockett RK (2014) Temporal variation in fecundity and spawning in the eastern oyster, Crassostrea virginica, in the Piankatank River, Virginia. J Shellfish Res 33:167-176

Marshall TC, Slate J, Kruuk LEB, Pemberton JM (1998) Statistical confidence for likelihood-based paternity inference in natural populations. Mol Ecol 5:639-655

Meirmans PG, Van Tienderen PH (2004) GENOTYPE and GENODIVE: Two programs for the analysis of genetic diversity of asexual organisms. Mol Ecol Notes 4:792-794

Morvezen R, Charrier G, Boudry P, Chauvaud L, Breton F, Strand Ø et al. (2016) Genetic structure of a commercially exploited bivalve, the great scallop Pecten maximus, along the European coasts. Conserv Genet 17:57-67

Mroch RM, Eggleston DB, Puckett BJ (2012) Spatiotemporal variation in oyster fecundity and reproductive output in a network of no-take reserves. J Shellfish Res 31:1091-1101

Myers RA, Worm B (2003) Rapid worldwide depletion of predatory fish communities precipitated marked changes in coastal ecosystem structure and function. Nature 423:280-283

Nei M (1987) Molecular evolutionary genetics. Columbia University Press, New York, NY

Nei M (1973) Analysis of gene diversity in subdivided populations. Proc Nat Acad Sci USA 70:3321-3323

Newell RE (1988). Ecological changes in Chesapeake Bay: are they the result of overharvesting the American oyster (Crassostrea virginica)? In: Lych MP, Krome EC (eds). Understanding the estuary: advances in Chesapeake Bay research Chesapeake Research Consortium Publication 129 CPB/TRS 24/88, pp. 536-546.

Oliehoek PA, Windig JJ, van Arendonk JAM, Bijma P (2006) Estimating relatedness between individuals in general populations with a focus on their use in conservation programs. Genetics 173:483-496

Palstra FP, Ruzzante DE (2008) Genetic estimates of contemporary effective population size: What can they tell us about the importance of genetic stochasticity for wild population persistence? Mol Ecol 71:301-314

Plough LV (2016) Genetic load in marine animals: a review. Curr Zool 62:567-579

Plough LV, Shin G, Hedgecock D (2016) Genetic inviability is a major driver of type III survivorship in experimental families of a highly fecund marine bivalve. Mol Ecol 25:895-910

Plough LV (2018) Fine-scale temporal analysis of genotype-dependent mortality at settlement in the Pacific oyster Crassostrea gigas. J Exp Mar Biol Ecol 501:90-98

Powell EN, Cummins H (1985) Are molluscan maximum life spans determined by long-term cycles in benthic communities? Oecologia 67:177-182

Powell EN, Morson JM, Ashton-Alcox KA, Kim Y (2013) Accommodation of the sex ratio in eastern oysters Crassostrea virginica to variation in growth and mortality across the estuarine salinity gradient in Delaware Bay. J Mar Biol Assoc UK 93:533-555

R Core Team (2017) R: A language and environment for statistical computing. R Foundation for Statistical Computing, Vienna, Austria, https://www.R-project.org/

Reece KS, Ribeiro WL, Gaffney PM, Carnegie RB, Allen SK (2004) Microsatellite marker development and analysis in the eastern oyster (Crassostrea virginica): Confirmation of null alleles and non-mendelian segregation ratios. J Hered 95:346-352

Rice WR (1989) Analyzing tables of statistical tests. Evolution 43:223-225

Rose CG, Paynter KT, Hare MP (2006) Isolation by distance in the eastern oyster, Crassostrea virginica, in Chesapeake Bay. J Hered 97:158-170

Rothschild BJ, Ault JS, Goulletquer P, Heral M (1994) Decline of the Chesapeake Bay oyster population: a century of habitat destruction and overfishing. Mar Ecol Prog Ser 111:29-40

Ryman N, Laikre L (1991) Effects of supportive breeding on the genetically effective population size. Conserv Biol 5:325-329

Schuelke M (2000) An economic method for the fluorescent labeling of PCR fragments. Nat Biotechnol 18:233-234

Van Oosterhout C, Hutchinson WF, Wills DPM, Shipley P (2004) MICRO-CHECKER: software for identifying and correcting genotyping errors in microsatellite data. Mol Ecol Notes $4: 535-538$ 
Waal SD, Balkhair M, Al-Mashikhi A, Khoom S (2013) Investigating the translocation and seeding of wild Haliotis mariae Wood, 1828, in the Sultanate of Oman. J Shellfish Res 32:315-323

Wallace RK, Waters P, Rikard FS (2008) Oyster Hatchery Techniques. Publication 4302, Southern Region Aquaculture Center, Stoneville, MS

Wang J (2011) COANCESTRY: a program for simulating, estimating and analysing relatedness and inbreeding coefficients. Mol Ecol Res 11:141-145

Wang Y, Guo X (2007) Development and characterization of ESTSSR markers in the eastern oyster Crassostrea virginica. Mar Biotechnol 9:500-511

Wang YP, Shi YH, Guo XM (2009). Identification and characterization of 66 EST-SR Markers in the eastern oyster Crassostrea virginica (Gmelin). J Shellfish Res 28:227-234

Waples R (2005) Genetic estimates of contemporary effective population size: to what time periods do the estimates apply? Mol Ecol 14:3335-3352

Waples RS (2016) Tiny estimates of the $N_{\mathrm{e}} / N$ ratio in marine fishes: are they real? J Fish Biol 89:2479-2504

Waples RS, Antao T, Luikart G (2014) Effects of overlapping generations on linkage disequilibrium estimates of effective population size. Genetics 197:769-780
Waples RS, Do C (2008) LDNE: A program for estimating effective population size from data on linkage disequilibrium. Mol Ecol Resour 8:753-756

Waples RS, Do C (2010) Linkage disequilibrium estimates of contemporary $\mathrm{Ne}$ using highly variable genetic markers: a largely untapped resource for applied conservation and evolution. Evol Appl 3:244-262

Waples RS, Hindar K, Karlsson S, Hard JJ (2016) Evaluating the Ryman-Laikre effect for marine stock enhancement and aquaculture. Curr Zool 62:617-627

Waples RS, Waples RK (2011) Inbreeding effective population size and parentage analysis without parents. Mol Ecol Res 11:162-171

Wedekind C, Rudolfsen G, Jacob A, Urbach D, Müller R (2007) The genetic consequences of hatchery-induced sperm competition in a salmonid. Biol Cons 137:180-188

Weir BS (1996) Genetic data analysis II: methods for discrete population genetic data. Sinauer Associates, Sunderland, MA

Westby SR, Sowers A, Slacum W, Paynter K (2017) 2016 Oyster reef monitoring report. NOAA, Silver Spring, MD

Withler RE, Beacham TD (1994) Genetic consequences of the simultaneous or sequential addition of semen from multiple males during hatchery spawning of chinook salmon (Oncorhynchus tshawytscha). Aquaculture 126:11-23 